\title{
A rel Mutation Abolishes the Enzyme Induction Needed for Actinomycin Synthesis by Streptomyces antibioticus
}

\author{
Kozo OCHI \\ Exploratory Research Laboratories, Fujisawa Pharmaceutical Co., Ltd., \\ 5-2-3 Toyosato-machi, Tsukuba-gun, Ibaraki 300-26, Japan
}

Received September 12, 1986

\begin{abstract}
A relaxed ( $\mathrm{rel}$ ) mutant was found among thirty spontaneous thiopeptin-resistant isolates of Streptomyces antibioticus strain 3720, an actinomycin-producing strain, which showed severely reduced ability to accumulate ppGpp during a nutritional shift-down. The pool size of GTP decreased markedly in the parental strain, but to a lesser extent in the rel mutant. The rel mutant did not show the induction of an enzyme, phenoxazinone synthase, which is involved in the biosynthesis of actinomycin. No negative effect of the rel mutation was observed on a constitutive enzyme, kynurenine formamidase, which also plays a role in actinomycin synthesis. The mutant also failed to produce melanin, but still retained the ability to form aerial mycelium and spores, although the onset of the formation of aerial mycelium was markedly delayed. Neither the phenoxazinone synthase activity nor the kynurenine formamidase activity was affected by ppGpp in vitro. It is suggested tha the stringent response ( $\mathrm{ppGpp}$ ) may be generally essential for the induction of enzymes involved in secondary metabolism.
\end{abstract}

Members of the genus Streptomyces have distinct characteristics, such as the abilities to develop aerial mycelium and conidiospores, and to produce numerous antibiotics. Therefore, Streptomyces are excellent organisms in which to study both differentiation and secondary metabolism. ${ }^{1)}$ Secondary metabolism is easier to study than morphological differentiation, especially in Streptomyces, because aerial mycelium is produced only on solid media, while antibiotics are produced both on solid media and in liquid culture. Thus, biochemical analysis of secondary metabolism can be performed rather easily. Taking secondary metabolism as "physiological differentiation," the initiation process through which secondary metabolism starts in cells was studied. ${ }^{2 \sim 5)}$

When cells encounter adverse environmental conditions such as nutrient limitation, they show the stringent response, accumulating ppGpp (guanosine-5'-diphosphate- $3^{\prime}$-diphosphate) and pppGpp (guanosine-5'-triphosphate- $3^{\prime}$-diphosphate), which are believed to be responsible for the stringent response.
The stringent response can be avoided by the introduction of genes with the relaxed genotype (for review, see refs. 6 and 7). Since ppGpp and pppGpp are synthesized on ribosomes through the catalitic action of an enzyme (stringent factor), a certain disturbance of the ribosomal conformation by a mutation or by a drug which binds to ribosomes might result in the failure to produce ppGpp and pppGpp. This was the case for Bacillus subtilis; the accumulation of ppGpp and pppGpp was abolished by adding small amounts of chloramphenicol or fusidic acid, ${ }^{8)}$ or by introducing a thiostrepton-resistant genotype ( $t s p-6=$ $\mathrm{relC}$ ), which resulted in a lack of ribosomal protein BS-L11.9,10) The most recent study indicated that the production of the antibiotic, formycin, by Streptomyces sp. MA406-A-1 is initiated by the stringent response (ppGpp) produced in response to nutrient limitation. ${ }^{5}$

Investigation of a relaxed $(\mathrm{rel})$ mutant of Streptomyces antibioticus with thiopeptinresistance isolated in this study showed that the normal rel gene function is needed for the induction of an enzyme, phenoxazinone syn- 
thase, which is believed to mediate actinomycin synthesis. To my knowledge, this is the first report of an essential role of the rel gene product (ppGpp) in the induction of an enzyme needed for a typical secondary metabolic process, antibiotic biosynthesis.

\section{MATERIALS AND METHODS}

Chemicals. $N$-Formylkynurenine was purchased from Calbiochem. 3-Hydroxyanthranilic acid and galactose (special grade) were from Nakarai Chemicals. $\left[2{ }^{14} \mathrm{C}\right]-$ Uracil was from New England Nuclear. Thiopeptin (an analogue of thiostrepton) was a commercial product of our company.

Strains and growth conditions. Streptomyces antibioticus strain 3720 (=ATCC 14888), a prototrophic actinomycin producing strain, was used. Spontaneous thiopeptinresistant mutants were obtained. as resistant colonies, which developed 24 days after the spreading of spores on sporulation agar (see below) supplemented with $0.5 \%$ polypeptone and $3 \mu \mathrm{g} / \mathrm{ml}$ of thiopeptin.

The sporulation agar contained (per liter): soluble starch, $4 \mathrm{~g}$; yeast extract, $4 \mathrm{~g}$; malt extract, $10 \mathrm{~g}$; and agar, $20 \mathrm{~g}$ (adjusted to $\mathrm{pH} 7.0$ with $\mathrm{NaOH}$ ). The synthetic medium (suitable for actinomycin production) was the same as the galactose/glucose/glutamate medium described by Gallo and Katz, ${ }^{11)}$ except that $0.2 \%$ instead of $0.1 \%$ glucose was contained. [Glucose at concentrations greater than $0.2 \%$ reduced the actinomycin formation.] The maltose/polypeptone/yeast extract medium (MPY-medium; suitable as a complex medium for actinomycin production) was described previously. ${ }^{5)}$

The cells, grown in NZ-amine medium $\left.{ }^{11}\right)(50 \mathrm{ml}$ in a $250 \mathrm{ml}$ flask) at $30^{\circ} \mathrm{C}$ for $30 \mathrm{hr}$, were harvested by centrifugation, washed twice with $100 \mathrm{ml}$ saline $(0.9 \% \mathrm{NaCl})$ and then resuspended in the original volume of saline. The washed cells $(1 \mathrm{ml})$ were inoculated into $50 \mathrm{ml}$ of the synthetic medium or of the synthetic medium supplemented with vitamin-free Casamino acids (in a $250 \mathrm{ml}$ flask), and then cultured at $30^{\circ} \mathrm{C}$ on a rotary shaker (230 rpm).

Assaying of nucleotide pools. The pool sizes of nucleotides, including ppGpp and pppGpp, were determined, after extraction with $1 \mathrm{M}$ formic acid, by means of HPLC on a column of Particil PXS 10-25 SAX (Whatman), as described in detail previously. ${ }^{5)}$

Enzyme assays. Crude enzyme extracts were prepared by sonical disruption (1 2 min) of cells suspended in deionized water, followed by centrifugation $(15,000 \times g$, $20 \mathrm{~min}$ at $3^{\circ} \mathrm{C}$ ). The supernatant used as the crude enzyme preparation contained $6 \sim 10 \mathrm{mg}$ protein per $\mathrm{ml}$.
Phenoxazinone synthase was assayed by the method described by Katz and Weissbach, ${ }^{12)}$ using 3-hydroxyanthranilic acid as a substrate. The incubation mixture consisted of $0.3 \mathrm{ml}$ of $6.6 \mathrm{~mm}$ 3-hydroxyanthranilic acid (neutralized with $\mathrm{NaOH}), 0.3 \mathrm{ml}$ of $0.8 \mathrm{M}$ potassium acetate buffer $(\mathrm{pH}$ 5.3), $5 \sim 20 \mu \mathrm{l}$ of the crude enzyme preparation and deionized water to give a final volume of $3 \mathrm{ml}$. The reaction was carried out at $37^{\circ} \mathrm{C}$ for $15 \mathrm{~min}$. The enzyme activity was determined by measuring the increase in optical density at $452 \mathrm{~nm}$ (molar extinction coefficient of the product $\left.=1.80 \times 10^{4}\right)$. Kynurenine formamidase was assayed by the method described by Brown et al. ${ }^{13)}$ using $N$ formyl-L-kynurenine as a substrate. The incubation mixture consisted of $0.3 \mathrm{ml}$ of $10 \mathrm{~mm} N$-formyl-L-kynurenine, $0.3 \mathrm{ml}$ of $0.5 \mathrm{M}$ potassium phosphate buffer $(\mathrm{pH} 7.4)$, $10 \sim 40 \mu \mathrm{l}$ of the crude enzyme preparation and deionized water to give a final volume of $3 \mathrm{ml}$. The reaction was carried out at $30^{\circ} \mathrm{C}$ for $10 \mathrm{~min}$. The enzyme activity was determined by measuring the increase in optical density at $365 \mathrm{~nm}$ (molar extinction coefficient of the product $=$ $\left.4.53 \times 10^{3}\right)$. Protein was determined by the method of Lowry et al. with serum albumin as a standard.

Assaying of actinomycin or RNA synthesis. Actinomycin was assayed spectrophotometrically ${ }^{14)}$ at $443 \mathrm{~nm}$ after extraction with ethyl acetate. If the amount of actinomycin produced in the medium was less than $10 \mu \mathrm{g} / \mathrm{ml}$, it was determined by a disk-plate method with Bacillus subtilis ATCC 6633 as a test organism (measurable down to $1 \mu \mathrm{g}$ / $\mathrm{ml}$ of actinomycin).

RNA synthesis was determined as described in detail previously. ${ }^{51}$

\section{RESULTS AND DISCUSSION}

\section{Accumulation of ppGpp by S. antibioticus}

The ability of Streptomyces antibioticus to accumulate ppGpp and pppGpp was first examined. When cells are transferred from a nutritionally rich to a nutritionally poor one they have to adapt to the absence of amino acids. Such starvation conditions leading to amino acid deficiency might increase the fraction of uncharged tRNA, and thus the stringent response might be transiently effective; this was the case for Streptomyces sp. MA406A-1.5) A similar approach was used for $S$. antibioticus. Unlike Streptomyces sp. MA406A-1, the cells of $S$. antibioticus, growing in synthetic medium supplemented with $1 \%$ Casamino acids, did not have the ability to accumulate ppGpp or pppGpp (Table I). The cells, however, were capable of accumulating 
Table I. Effect of the Growth Conditions on the Ability of Cells to ACCumulate ppGpp after a Nutritional Shift-down

\begin{tabular}{|c|c|c|c|c|c|c|}
\hline \multirow{2}{*}{$\begin{array}{c}\text { Grown with } \\
\text { Casamino acids } \\
\text { of }\end{array}$} & \multicolumn{6}{|c|}{ Shifted down after growth for: } \\
\hline & $8 \mathrm{hr}$ & $12 \mathrm{hr}$ & $\begin{array}{r}16 \mathrm{hr} \\
\text { ppGpp }\end{array}$ & $\begin{array}{l}20 \mathrm{hr} \\
\text { dry wt) }\end{array}$ & $24 \mathrm{hr}$ & $28 \mathrm{hr}$ \\
\hline $1 \%$ & 5 & 4 & 3 & 5 & ND & ND \\
\hline $2 \%$ & 4 & 26 & 40 & 6 & ND & ND \\
\hline $2.5 \%$ & 18 & 42 & 78 & 58 & 23 & 20 \\
\hline
\end{tabular}

Cells of strain 3720 , grown in synthetic medium supplemented with various amounts of Casamino acids (vitaminfree) for the indicated times, were harvested and transferred to fresh synthetic medium without Casamino acids. After 10 min incubation with shaking, the cells were harvested and extracted for the assaying of ppGpp. The pool size of ppGpp just before the transfer of cells grown for $16 \mathrm{hr}$ to conditions without Casamino acids was in the range of $3 \sim 6 \mathrm{pmol} / \mathrm{mg}$ dry wt.

ND, not determined.

marked amounts of ppGpp 10 min after a shift-down, if the cells had previously been grown with $2.5 \%$ instead of $1 \%$ Casamino acids; this ability was maximal for the cells grown for $16 \mathrm{hr}$ (mid-exponential) and to a lesser extent for the cells grown for $8 \mathrm{hr}$ (early exponential) or $24 \mathrm{hr}$ (post exponential) (Table I). These results are in agreement with those for Bacillus subtilis and Escherichia coli, both of which showed the maximal capacity to form ppGpp during the mid-exponential growth phase. ${ }^{15,16)}$ The size of the pppGpp pool was only one-fifth or less compared to that of ppGpp (not shown). Thus, one must take the growth conditions into consideration when examining the ability to accumulate ppGpp.

\section{Isolation of a relaxed mutant}

The addition of Casamino acids $(1 \sim 3 \%)$ to the synthetic medium markedly enhanced the growth rate of cells, while actinomycin production was completely suppressed during 5 days incubation. This suppression might be due to interference with the intracellular accumulation of ppGpp, as was the case for the antibiotic production by $B$. subtilis Marburg ${ }^{3)}$ or the formycin production by Streptomyces sp. MA406-A-1. ${ }^{5)}$ To assess the contribution of the accumulation of ppGpp to the triggering of the formation of actinomycin, an attempt was made at the isolation of relaxed ( $\mathrm{rel}$ ) mutants, which might lack the ability to pro- duce ppGpp. Since relaxed mutants (relC) were found among thiostrepton-resistant isolates of B. subtilis, ${ }^{9.10)}$ a search was made for rel mutants of $S$. antibioticus among spontaneous thiopeptin (an analogue of thiostrepton)-resistant isolates. A number of thiopeptin-resistant colonies developed on plates containing $3 \mu \mathrm{g} / \mathrm{ml}$ of thiopeptin after 24 days incubation. Among them, 30 strains selected randomly were tested as to their ability to produce ppGpp. Cells of each strain growing exponentially with $2.5 \%$ Casamino acids were transferred into fresh synthetic medium without Casamino acids, as described above. After $10 \mathrm{~min}$ incubation, the cells were collected and extracted, and the extracts were analyzed by HPLC. A strain, designated as No. 49 , was found to accumulate a severely reduced amount of ppGpp, compared with the parental strain (Fig. 1). The other 29 strains examined accumulated as much ppGpp as the parental strain (not shown). Changes in the nucleotide pools of the parental strain during a shift-down were much more drastic than in the case of mutant No. 49; it was especially notable that the pool size of GTP had decreased by $62 \% \quad 10 \mathrm{~min}$ after a shift-down of the parental strain, but to a lesser extent in mutant No. 49 (Table II).

The RNA synthesis of the parental strain was markedly reduced upon a nutritional shiftdown, while mutant No. 49 showed continued 
Table II. Changes in the Intracellular Concentrations of Nucleoside Triphosphates and ppGpp after a Shift-down from Synthetic Medium Supplemented with $2.5 \%$ Casamino Acids to Synthetic Medium Lacking Casamino Acids

\begin{tabular}{|c|c|c|c|c|c|c|}
\hline Strain & $\begin{array}{c}\text { Time of } \\
\text { incubation }\end{array}$ & UTP & \multicolumn{3}{|c|}{$(\mathrm{pmol} / \mathrm{mg}$ dry wt $)$} & ppGpp \\
\hline Parent & Zero-time & 679 & 474 & 1850 & 652 & 5 \\
\hline$(3720)$ & $10 \mathrm{~min}$ & 790 & 1180 & 4490 & 248 & 82 \\
\hline Mutant & Zero-time & 995 & 878 & 2690 & 698 & $<4$ \\
\hline (No. 49) & $10 \mathrm{~min}$ & 780 & 817 & 2590 & 403 & 12 \\
\hline
\end{tabular}

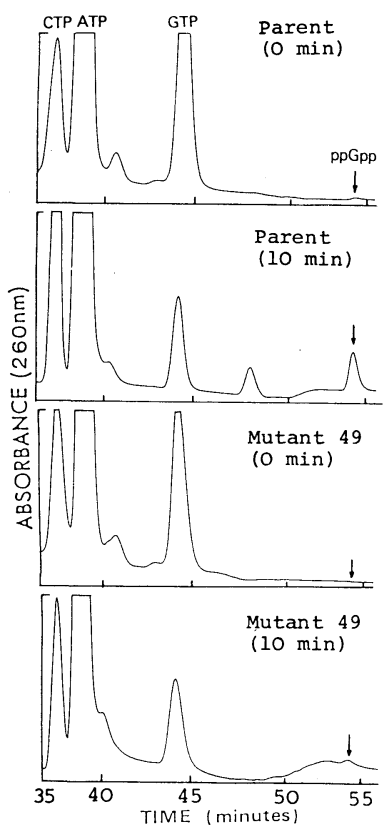

Fig. 1. Elution Profiles of Nucleotides Extracted from Cells of the Parental Strain (3720) and Mutant No. 49 after Casamino Acids Deprivation.

The strains, grown to the mid-exponential phase ( $16 \mathrm{hr}$ for the parent and $24 \mathrm{hr}$ for the mutant) in the synthetic medium plus $2.5 \%$ Casamino acids, were harvested and transferred to fresh synthetic medium lacking Casamino acids. After $10 \mathrm{~min}$ incubation with shaking, the cells were collected and extracted, and the extracts were then analyzed by HPLC. The samples applied were equivalent to $9 \sim 11 \mathrm{mg}$ cell dry wt for each profile. The scale for absorbance is $0 \sim 0.03$.

RNA synthesis for at least $20 \mathrm{~min}$ at a rate rather higher than that in the presence of Casamino acids (Fig. 2). Thus, mutant No. 49 exhibited the relaxed phenotype with respect to RNA synthesis. The relaxed mutant thus obtained revealed no requirement for any nu-

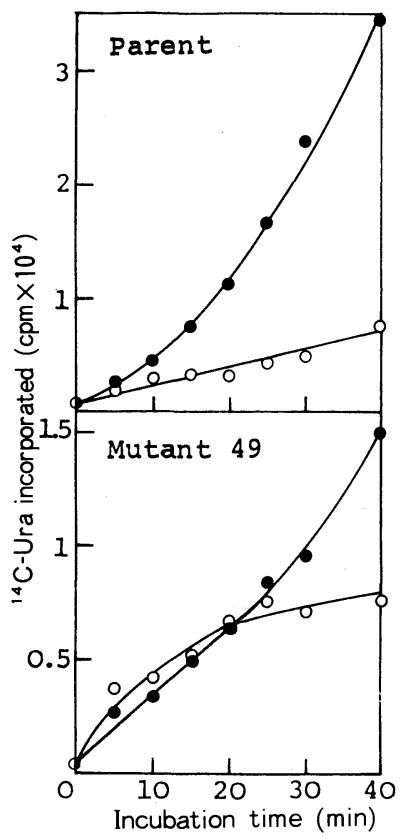

FIG. 2. Effect of Casamino Acids Deprivation on RNA Synthesis by Cells of Streptomyces antibioticus Strain 3720 and Mutant Strain No. 49.

Cells, grown with $2.5 \%$ Casamino acids, as in Fig. 1, were transferred to the synthetic medium containing $\left[2-{ }^{14} \mathrm{C}\right]$ uracil with (O) or without $(\bigcirc) 2.5 \%$ Casamino acids, and then incubated with shaking for $40 \mathrm{~min}$.

trients, as it grew normally in synthetic medium and was resistant to thiopeptin up to $10 \mu \mathrm{g} / \mathrm{ml}$, as determined after 20 days incubation on agar plates. [Growth of the parental strain was completely suppressed with $2 \mu \mathrm{g} / \mathrm{ml}$ of thiopeptin.] The rel mutant No. 49 might be tentatively classified as a relC mutant, in analogy with the mutant of $B$. subtilis which lacks ribosomal protein BS-L11,9,10) but further work at the molecular level is required to 
confirm this directly. The other 29 thiopeptinresistant isolates may include mutants deficient in thiopeptin uptake and ones with altered ribosomal conformations, but these alterations in the membrane or the ribosomal conformation (if any) apparently did not affect the ability to produce ppGpp.

\section{Characterization of the rel mutant}

The rel mutation resulted in numerous pleiotropic effects: the most striking one was that the rel mutant lost the ability to produce actinomycin in both liquid and agar-plate cultures. Actinomycin amounted were less than detectable level (i.e., $1 \mu \mathrm{g} / \mathrm{ml}$ ) in both the synthetic medium and MPY-medium. The parental strain produced $110 \mu \mathrm{g} / \mathrm{ml}$ (at 5 days) and $30 \mu \mathrm{g} / \mathrm{ml}$ (at 2 days) of actinomycin in the synthetic medium and MPY-medium, respectively. The rel mutant also lost the ability to produce the black pigment, melanin, which is one of the distinctive characteristics of $S$. antibioticus. Although the rel mutant still retained the ability to form aerial mycelium and spores when cultured on sporulation agar, the amounts were less than those produced by the parental strain, and the onset of the formation of aerial mycelium was drastically delayed ( 2 days for the parent, but 8 days for the rel mutant). The aerial mycelium formation of several Streptomyces spp. examined was shown to be initiated by a partial decrease in GTP content. ${ }^{4}$ The delayed appearance of aerial mycelium in the $S$. antibioticus rel mutant may be accounted for at least partially by the reduced decrease in GTP content upon amino acid deficiency (see Table II). The properties of the $S$. antibioticus rel mutant described above are well coincident with those found for rel mutants of Streptomyces $\mathrm{sp}$. MA406-A-1.5) To elucidate the properties of these rel mutations, a genetic study is clearly required.

\section{Effect of the rel mutation on enzyme induction}

Finally, whether or not the loss of the ability to produce actinomycin in the rel mutant resulted from a failure of expression of enzyme(s) involved in actinomycin synthesis was examined. Two enzymes, kynurenine formamidase and phenoxazinone synthase, were investigated as suitable probes. [See ref. 17 for their mediation steps in the actinomycin biosynthetic pathway.] As reported by Katz and coworkers, ${ }^{11,18)}$ S. antibioticus strain 3720 showed phenoxazinone synthase induction prior to the beginning of actinomycin synthesis (a few data are presented in Table III). In contrast, rel mutant No. 49 did not show phenoxazinone synthase induction during 3 days cultivation (Table III), indicating that the normal rel gene function was needed for the induction of this enzyme activity. This is in contrast to the results obtained for actinomycin-nonproducing strains, which were found after curing treatment with acriflavin and still showed phenoxazinone synthase induction. ${ }^{17)}$

Unlike in the case of phenoxazinone synthase, the rel mutant produced formamidase constitutively: the activities were $2 \sim 3$ folds higher than those produced by the $\mathrm{rel}^{+}$parental strain (Table III). Apparently, the rel gene function (and thus ppGpp) was unnecessary for the expression of formamidase. This seems to be reasonable because formamidase is also utilized for a primary metabolic process, NAD biosynthesis. In another actinomycin producing organism, Streptomyces parvulus, two forms of formamidase have been found; one of them is a constitutive and the other an inducible (derepressible) isozyme, the activity of which appears just prior to actinomycin production. ${ }^{13)}$ Since $S$. antibioticus used here did not show increased formamidase activity during the onset of actinomycin production, only the constitutive form may exist in it.

The physiological concentrations of ppGpp $(0.2 \sim 2 \mathrm{~mm})$ produced in vitro neither inhibited nor stimulated the phenoxazinone synthase or kynurenine formamidase activity (Table IV). The reduced phenoxazinone synthase activity of the rel mutant remained at a low level in the presence of added ppGpp. Thus, it is highly likely that the reduced or increased enzyme activity of the rel mutant is due to an event at 
Table III. Kynurenine Formamidase and Phenoxazinone Synthase in the Parental Strain (3720) and Relaxed Mutant (49) of $S$. antibioticus Growing in Synthetic Medium

\begin{tabular}{|c|c|c|c|c|c|c|c|c|}
\hline \multirow{3}{*}{ Strain } & \multicolumn{8}{|c|}{ Specific activity (nmol of product $/ \mathrm{mg}$ of $\operatorname{protein} / \mathrm{min}$ ) } \\
\hline & \multicolumn{4}{|c|}{ Kynurenine formamidase } & \multicolumn{4}{|c|}{ Phenoxazinone synthase } \\
\hline & $0 \mathrm{hr} *$ & $12 \mathrm{hr}$ & $48 \mathrm{hr}$ & $72 \mathrm{hr}$ & $0 \mathrm{hr}^{*}$ & $12 \mathrm{hr}$ & $48 \mathrm{hr}$ & $72 \mathrm{hr}$ \\
\hline Parent $\left(\mathrm{rel}^{+}\right)$ & 123 & 62 & 53 & 41 & 9 & 12 & 132 & 156 \\
\hline Mutant (rel) & 378 & 213 & 173 & 87 & 3 & 14 & 15 & 19 \\
\hline
\end{tabular}

* The enzyme preparation for $0 \mathrm{hr}$ was obtained from cells grown in NZ-amine medium for $30 \mathrm{hr}$.

TABLE IV. In Vitro EFFECTS OF ppGpp ON KYNURENINE FormamidASE and Phenoxazinone Synthase

\begin{tabular}{|c|c|c|c|c|}
\hline \multirow{3}{*}{$\begin{array}{l}\text { ppGpp } \\
(\mathrm{mM})\end{array}$} & \multicolumn{4}{|c|}{$\begin{array}{c}\text { Specific activity } \\
(\mathrm{nmol} \text { of product } / \mathrm{mg} \text { of protein } / \mathrm{min})\end{array}$} \\
\hline & \multicolumn{2}{|c|}{ Kynurenine formamidase } & \multicolumn{2}{|c|}{ Phenoxazinone synthase } \\
\hline & Parent $\left(\mathrm{rel}^{+}\right)$ & Mutant (rel) & Parent $\left(\mathrm{rel}^{+}\right)$ & Mutant (rel) \\
\hline None & 49 & 181 & 124 & 12 \\
\hline 0.2 & 47 & 174 & 118 & 12 \\
\hline 2 & 49 & 169 & 125 & 12 \\
\hline
\end{tabular}

The crude enzyme was prepared from cells grown in the synthetic medium for $48 \mathrm{hr}$. ppGpp was added to the assay mixture just before starting the reaction, to a final concentration of 0.2 or $2 \mathrm{~mm}$.

the transcriptional (or translational) level. Phenoxazinone synthase expression has been well shown to be the subject of catabolite repression, and is controlled at both the transcriptional and post-transcriptional levels. ${ }^{11,19)}$ Unlike the systems in E. coli, cAMP does not appear to mediate the repression of actinomycin synthesis in $S$. antibioticus. ${ }^{11,20)}$ Since the rel mutation resulted in a failure of induction (derepression) of phenoxazinone synthase, it is of interest to determine whether or not effects elicited by the stringent response (ppGpp) were exerted at the transcriptional and/or translational level, and could be superimposed on the suppressing effect of catabolite regulation. As will be reported elsewhere, a rel mutation of Streptomyces griseus also abolished the induction of enzymes involved in streptomycin biosynthesis. The normal rel gene function, therefore, may be generally needed for the triggering of the synthesis of inducible enzymes necessary for secondary metabolism.

Acknowledgment. The author wishes to thank Drs. M. Okuhara and M. Kohsaka for their encouragement during this study.

\section{REFERENCES}

1) K. F. Chater, "Microbial Development," ed. by R. Losick and L. Shapiro, Cold Spring Habor Laboratory, Cold Spring Habor, New York, 1984, pp. $89 \sim 116$.

2) K. Ochi, Y. Saito, K. Umehara, I. Ueda and M. Kohsaka, J. Gen. Microbiol., 130, 2007 (1984).

3) K. Ochi and S. Ohsawa, J. Gen. Microbiol., 130, 2473 (1984).

4) K. Ochi, J. Gen. Microbiol., 132, 299 (1986).

5) K. Ochi, J. Gen. Microbiol., 132, 2621 (1986).

6) M. Cashel, Annu. Rev. Microbiol., 29, 301 (1975).

7) J. A. Gallant, Annu. Rev. Genet., 13, 393 (1979).

8) K. Ochi and E. Freese, J. Gen. Microbiol., 129, 3709 (1983).

9) I. Smith, P. Paress and S. Pestka, Proc. Natl. Acad. Sci. U.S.A., 75, 5993 (1978).

10) I. Smith, P. Paress, K. Gabane and E. Dubnau, Mol. Gen. Genet., 178, 271 (1980). 
11) M. Gallo and E. Katz, J. Bacteriol., 109, 659 (1972).

12) E. Katz and H. Weissbach, J. Biol. Chem., 237, 882 (1962).

13) D. D. Brown, M. J. M. Hitchcock and E. Katz, Arch. Biochem. Biophys., 202, 18 (1980).

14) E. Katz and H. Weissbach, J. Biol. Chem., 238, 666 (1963).

15) P. Fortnagel and R. Bergman, Biochem. Biophys. Res. Commun., 56, 264 (1974).
16) S. Ramagopal, Biochim. Biophys. Acta, 435, 128 (1976).

17) K. Ochi, J. Bacteriol., 150, 598 (1982).

18) R, Marshall, B. Redfield, E. Katz and H. Weissbach, Arch. Biochem. Biophys., 123, 317 (1968).

19) G. H. Jones, J. Bacteriol., 163, 1215 (1985).

20) S. Chatterjee and L. C. Vining, Can. J. Microbiol., 28, 1396 (1982). 